\title{
Prevention of Helicobacter pylori infection by lactobacilli in a gnotobiotic murine model
}

\author{
A M A Kabir, Y Aiba, A Takagi, S Kamiya, T Miwa, Y Koga
}

\begin{abstract}
Background-Helicobacter pylori is a bacterium which causes gastric inflammatory diseases. Oral inoculation of $H$ pylori usually results in only a temporary colonisation without a successful infection in the stomach of conventional mice in which lactobacilli are the predominant indigenous bacteria.

Aim-To determine whether lactobacilli exert an inhibitory effect on colonisation by $H$ pylori in the stomach.

Methods-The effects of $H$ pylori on attachment to murine and human gastric epithelial cells and the $H$ pylori mediated release of interleukin-8 (IL-8) by these cells were examined in vitro. Lactobacillus salivarius infected gnotobiotic BALB/c mice and control germ free mice were inoculated orally with $H$ pylori to examine whether $L$ salivarius can inhibit colonisation by $\boldsymbol{H}$ pylori.

Results- $L$ salivarius inhibited both the attachment and IL-8 release in vitro. $H$ pylori could not colonise the stomach of $L$ salivarius infected gnotobiotic BALB/c mice, but colonised in large numbers and subsequently caused active gastritis in germ free mice. In addition, $L$ salivarius given after $H$ pylori implantation could eliminate colonisation by $\boldsymbol{H}$ pylori.

Conclusion-These findings suggest the possibility of lactobacilli being used as probiotic agents against $H$ pylori.

(Gut 1997; 41: 49-55)
\end{abstract}

Infectious Diseases

Y Aiba

Y Koga

Department of

Internal Medicine VI,

Tokai University

School of Medicine,

Isehara, Kanagawa,

Japan

A M A Kabir

A Takagi

T Miwa

Department of Microbiology, Kyorin University School of Medicine, Mitaka, Tokyo, Japan

S Kamiya

Research Department, Wakamoto

Pharmaceutical Co., Ohi-machi, Kanagawa,

Japan

Y Aiba

Correspondence to:

Dr Yasuhiro Koga

Department of Infectious

Diseases, Tokai University

School of Medicine, Isehara,

Kanagawa 259-11, Japan.

Accepted for publication

28 January 1997
Keywords: Helicobacter pylori; Lactobacillus salivarius; germ free mice; probiotics

Helicobacter pylori is a microaerophilic and Gram negative bacillus that causes chronic gastritis and peptic ulcer diseases. This bacterium is also suspected to be involved in the genesis of gastric cancer. ${ }^{1} H$ pylori infection usually occurs within a few years after birth and persists chronically thereafter. In developing countries, up to $80 \%$ of the population may become infected by age $20 .^{2}$ Administration of an effective vaccine thus needs to be carried out in such countries in order to prevent young people from being infected by $H$ pylori. However, the efficacy of a vaccine against this bacterium is still uncertain, because a natural immunity seems to be inadequate for curing the infection in spite of an active immune response at the site of colonisation of $H$ pylori. Moreover, the vaccine may also cause autoimmune inflammation since some protein species of $H$ pylori bear a close homology to such eukaryotic proteins as heat shock pro- teins. $^{34}$ Therefore, a new device free of such problems needs to be developed together with a conventional vaccine to achieve complete prevention of $H$ pylori infection.

Attachment to cells is a prerequisite for the colonisation of the epithelial surface by many bacteria and this phenomenon is mediated by the molecules on the bacterial surface, which subsequently recognise proteins or glycoconjugates on the surface of eukaryotic cells. An ultrastructural analysis of gastric mucosa infected with $H$ pylori in vitro showed this bacterium to adhere to the gastric epithelium strongly enough to cause an effacement of the epithelial microvilli and also form adherence pedestals. ${ }^{5}{ }^{6}$ Such close contact of $H$ pylor $i$ with the epithelium results in the secretion of cytokines such as interleukin-8 (IL-8) and IL-1, which are considered to play an important role in the occurrence of gastric lesions. ${ }^{7}$ It is thus expected that an agent capable of inhibiting the attachment of $H$ pylori could also prevent the colonisation and subsequent symptomatic gastric disease caused by this bacterium in the stomach.

The gastrointestinal (GI) tract is colonised by a variety of indigenous bacteria. Lactobacilli are the predominant bacteria found in the normal fasting stomach although their number is small, ranging from only 0 to $10^{3}$ per $\mathrm{ml}$ of fluid. ${ }^{8}$ The inhibitory effect of lactobacilli on the growth of $H$ pylori has been previously demonstrated in vitro. ${ }^{9}$ Karita et al ${ }^{1011}$ reported that the oral inoculation of $H$ pylori resulted in a continuous colonisation of the gastric mucosa in decontaminated mice; however the colonisation was only temporary in the non-decontaminated mice in which lactobacilli are the predominant indigenous inhabitants. It was thus suggested that lactobacilli exert an inhibitory effect on colonisation of the stomach by $H$ pylori. To evaluate this possibility, we have investigated whether lactobacilli inhibit the attachment of $H$ pylori to epithelial cells in vitro and whether the lactobacillus exerting such an inhibitory effect can also prevent the colonisation and development of inflammatory lesions in the stomach using a gnotobiotic murine model.

\section{Methods}

BACTERIAL STRAINS

$H$ pylori No 112 ( cag $^{+}$, vacuolating toxin $\left.{ }^{-}\right)$, No 130 (cag $A^{+}$, vacuolating toxin ${ }^{+}$), and No 135 ( cag $A^{+}$, vacuolating toxin ${ }^{+}$) were isolated by us from gastric biopsy materials of patients treated at Tokai University Hospital. $H$ pylori NCTC 11637 was purchased from the American Type Culture Collection (ATCC), Rockville, 
Maryland, USA. They were grown on Skirrow plates to count the number of colony forming units (CFU). Identification of clinical isolates such as $H$ pylori was done by Gram stain morphology and by using API CAMPY Kit (Biomeriux, Marcy-l'Etoile, France) after the colony was transferred to a brain/heart infusion agar plate (Difco Laboratories, Detroit, Michigan, USA). The cytotoxicity assay to detect the vacuolating toxin was performed by a previously described method. ${ }^{12}$ The colony of $H$ pylori was then transferred to Brucella broth (Difco Laboratories) containing 5\% FCS and incubated at $37^{\circ} \mathrm{C}$ for 72 hours. The broth cultures were harvested by centrifugation at $3000 \mathrm{~g}$ for 15 minutes, resuspended in a medium containing $10 \%$ skimmed milk and $1 \%$ sodium glutamate, and frozen at $-70^{\circ} \mathrm{C}$ until use. Using these procedures, the clinically isolated strains of $H$ pylori underwent in vitro passage four times and were then kept frozen as the stock for experimental use. For the adherence assay, $H$ pylori from the stock was cultured again in a brain/heart infusion agar (Difco) containing 5\% horse blood in $5 \% \mathrm{O}_{2}$, $10 \% \mathrm{CO}_{2}$, and $85 \% \mathrm{~N}_{2}$ at $37^{\circ} \mathrm{C}$ for four days and then used. For inoculation into mice, $H$ pylori from the stock was grown in Brucella broth containing $5 \% \mathrm{FCS}$ in the gas described above at $37^{\circ} \mathrm{C}$ for three days. Lactobacillus salivarius (WB1004) and $L$ brevis (WB1005) were provided by the Wakamoto Pharmaceutical Company, Tokyo, Japan. The number of CFU of lactobacilli was counted on BL agar (Nissui, Tokyo, Japan) and identified as Lactobacillus using the API $50 \mathrm{CHL}$ Kit (Biomeriux). For inoculation into mice, lactobacilli were grown in MRS broth (Difco) in $10 \% \mathrm{H}_{2}, 10 \% \mathrm{CO}_{2}$, and $85 \% \mathrm{~N}_{2}$ for one day. Enterococcus faecalis (No 19433) and Staphylococcus aureus (No 25923) were obtained from ATCC and grown on a BHI agar (Difco) plate.

\section{ADHERENCE ASSAY}

An adherence assay was carried out by the method of Dunn et $a^{13}$ with some modification. Briefly, $1 \times 10^{6}$ of Kato III, MKN45, or murine gastric epithelial cells and varying numbers of fluorescent (PKH26) labelled lactobacilli were suspended in Hank's gelatin salt solution (HGSS) and incubated at $37^{\circ} \mathrm{C}$ for 30 minutes in a $1.5 \mathrm{ml}$ tube with gentle shaking. Fluorescent (PKH2) labelled $H$ pylori suspended in $0.1 \mathrm{ml}$ HGSS was added to the tube and was incubated at $37^{\circ} \mathrm{C}$ for one hour. The nonadherent bacteria were removed by centrifugation with the addition of $9 \mathrm{ml} 15 \%$ sucrose solution at $1000 \mathrm{rpm}$ for 15 minutes. The cells were washed once with HGSS and were then analysed by flow cytometry using FACS Vandage (Becton Dickinson, Mountain View, California, USA). The machine was gated to include single cells but to exclude cell debris, clumps of cells, and non-adherent bacteria as described elsewhere. ${ }^{14}$ The labelling of $H$ pylor $i$ and lactobacillus with fluorescent dyes PKH2 (Dainippon Pharmaceutical Company, Tokyo, Japan) and PKH26 (Dainippon), respectively, was performed according to the manufacturer's instructions. The emission waves from $\mathrm{PKH} 2$ and PKH26 were $504 \mathrm{~nm}$ and $567 \mathrm{~nm}$, respectively. Kato III (gastric adenocarcinoma) and MKN45 (gastric carcinoma) cells were obtained from the Japanese Cancer Research Resources Bank (Tokyo, Japan). These cells were grown at $37^{\circ} \mathrm{C}$ in RPMI 1640 medium containing $10 \%$ FCS in $5 \% \mathrm{CO}_{2}$. Gastric epithelial cells were prepared from fresh stomachs of BALB/c germ free (GF) mice according to the method described by Kobayashi et al. ${ }^{15}$

ASSAY OF IL-8 PRODUCED IN CELL CULTURE To measure the amount of IL-8 in the culture supernatant, $5 \times 10^{5} \mathrm{MKN} 45$ cells were suspended in $1.8 \mathrm{ml}$ of RPMI 1640 medium containing $10 \% \mathrm{FCS}$ and incubated at $37^{\circ} \mathrm{C}$ on a 24-well dish. One day after the start of incubation, varying numbers of lactobacilli (suspended in $0.1 \mathrm{ml}$ of medium) were added to the dish, followed by $10^{8} \mathrm{H}$ pylori (suspended in $0.1 \mathrm{ml}$ of medium) $30 \mathrm{~min}$ later. Six to 24 hours after incubation at $37^{\circ} \mathrm{C}$, the supernatants were collected and IL-8 was measured by ELISA using the Quantikine Human IL-8 Immunoassay Kit (R\&D Systems, Minneapolis, Minnesota, USA).

\section{ANIMALS}

Animal treatment and care were carried out in accordance with the institutional guidelines of Tokai University. Male GF and specific pathogen free (SPF) BALB/c mice were obtained from Nippon Clea Inc. (Tokyo, Japan). GF mice were maintained in Trexler type flexible film plastic isolators with sterile food and water as described previously. ${ }^{16}$ For infection with $H$ pylori, five-week-old mice were orally inoculated on three consecutive days with $1 \times 10^{9}$ CFU of $H$ pylori that were freshly prepared and resuspended in $0.5 \mathrm{ml}$ of phosphate buffered saline. To colonise mice by lactobacilli, $1 \times 10^{9}$ CFU of lactobacilli suspended in $0.5 \mathrm{ml}$ of phosphate buffered saline were orally inoculated once into four-week-old mice.

SERUM ANTIBODY TITRE

Serum titre of IgG class antibody raised to $H$ pylori was measured by ELISA according to a method described previously. ${ }^{17}$ The antigen was a bacterial sonicate obtained by ultracentrifugation of $H$ pylori strain NCTC 11637. The absorbance reading was obtained from an appropriate dilution of serum whose titre was within the range in which a linear doseabsorbance relationship was available. A serum pool from GF mice at six weeks after infection with NCTC 11637 was regarded as the standard and was used to make the doseabsorbance plot.

\section{GASTRIC PATHOLOGY}

One half of each resected stomach along the greater curvature was fixed in $4 \%$ buffered formalin, and embedded in paraffin wax. Sections were stained with haematoxylin and eosin following standard procedures. 


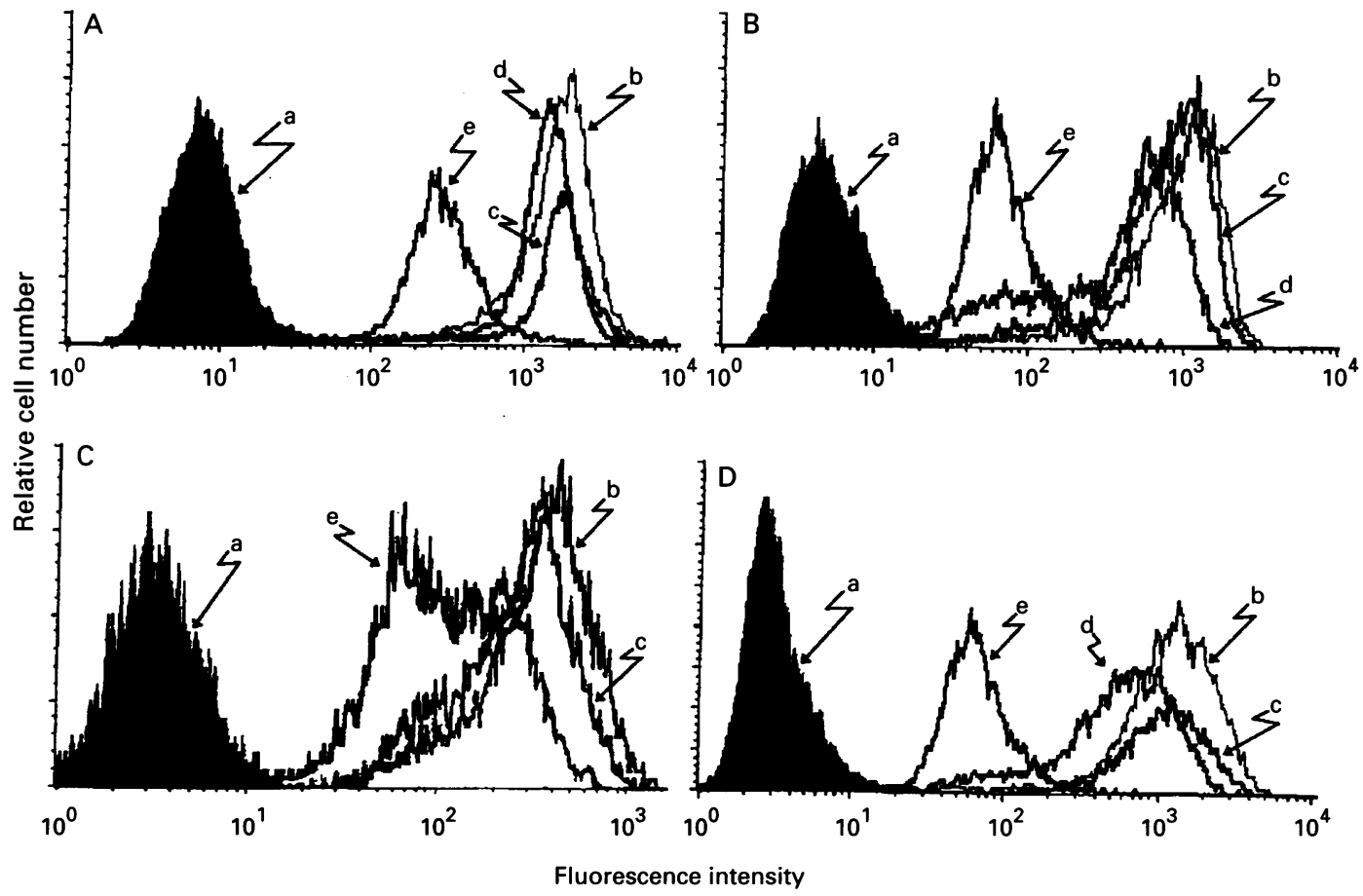

Figure 1: A flow cytometric analysis of $\mathrm{H}$ pylori adhesion. $1 \times 10^{9} \mathrm{PKH} 2$ labelled $\mathrm{H}$ pylori were added to the adhesion assay culture which consisted of Kato-III $(A), M K N 45(B)$, or murine gastric epithelial $(C)$ cells in the presence of $0(b)$, $1 \times 10^{7}(c), 1 \times 10^{8}(d)$, or $1 \times 10^{9}(e)$ of $\mathrm{L}$ salivarius. Curve $(a)$ shows the autofluorescence pattern of untreated cells. $D:$ $1 \times 10^{9} \mathrm{PKH} 2$ labelled $\mathrm{H}$ pylori were added to the culture of MKN45 cells in the absence of the other bacterium (b) or in the presence of $1 \times 10^{9} \mathrm{E}$ faecalis $(c), \mathrm{S}$ aureus $(d)$, or $\mathrm{L}$ salivarius $(e)$. Curve $(a)$ shows the autofluorescence pattern of untreated cells.

\section{Results}

INHIBITION OF ATTACHMENT OF H PYLORI TO GASTRIC EPITHELIAL CELLS BY LACTOBACILLI To assess the effect of lactobacilli on the attachment of $H$ pylori to gastric epithelial cells, $L$ salivarius, one of the indigenous lactobacilli found in the human upper GI tract, was added

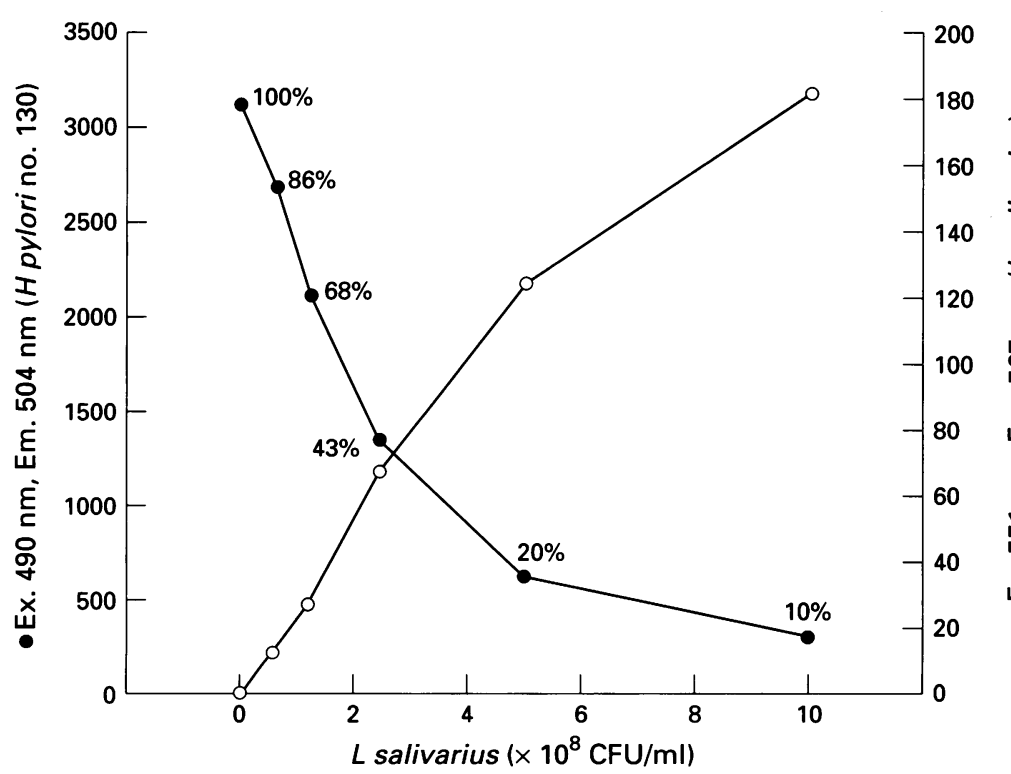

Figure 2: The relationship between the number of adherent $\mathrm{H}$ pylori and that of adherent $\mathrm{L}$ salivarius to the cells. $1 \times 10^{9} \mathrm{PKH} 2$ labelled $\mathrm{H}$ pylori and varying numbers $\left(0-10 \times 10^{8}\right)$ of PKH26 labelled $\mathrm{L}$ salivarius were mixed with $1 \times 10^{6} \mathrm{MKN} 45$ cells and incubated for an adherence assay. The fluorescent levels from PKH2 (closed circles;

emission wave, $504 \mathrm{~nm}$ ) and PKH26 (open circles; emission wave, $567 \mathrm{~nm}$ ) were analysed simultaneously by FACS while using different photodetectors. The relative cell number of $\mathrm{H}$ pylori deduced from the $504 \mathrm{~nm}$ fluorescent level is denoted in the figure and is regarded as $100 \%$ when no $\mathrm{L}$ salivarius was added. to the culture for an adherence assay that consisted of fluorescent labelled $H$ pylori and human gastric epithelial cell lines or murine gastric epithelial cells (fig 1). When the same number of $L$ salivarius $\left(1 \times 10^{9}\right)$ as that of $H$ pylori No 130 was added to the assay culture, the number of $H$ pylori adhering to both the Kato III and MKN45 cells decreased to less than one tenth the original number (fig 1A, B). Such a marked reduction in the attachment of $H$ pylori to the cells by $L$ salivarius was also found when murine gastric epithelial cells were used as indicator cells (fig 1C). A quantitative analysis of adherence inhibition using MKN45 cells demonstrated a close reverse correlation between the number of added $L$ salivarius and that of $H$ pylori attached to the cells (fig 2). Based on these plots, it was estimated that approximately $2 \times 10^{8} \mathrm{~L}$ salivarius organisms were sufficient to reduce the number of adhering $H$ pylori from $1 \times 10^{9}$ to half that number. $L$ brevis and $L$ acidophilus also exhibited a significant but less marked inhibitory effect on the attachment of $H$ pylori to the gastric epithelial cell lines (data not shown). In contrast to lactobacilli, neither Enterococcus faecalis nor Staphylococcus aureus, which are also found in the microflora of the GI tract, exerted any significant inhibitory effect on the adherence of $H$ pylori to these cells (fig 1D).

SUPPRESSION OF H PYLORI MEDIATED RELEASE OF IL-8

To confirm the lactobacilli mediated inhibition of $H$ pylori attachment, lactobacilli were added to the culture in which MKN45 cells were stimulated to secrete IL- 8 by the attachment of 

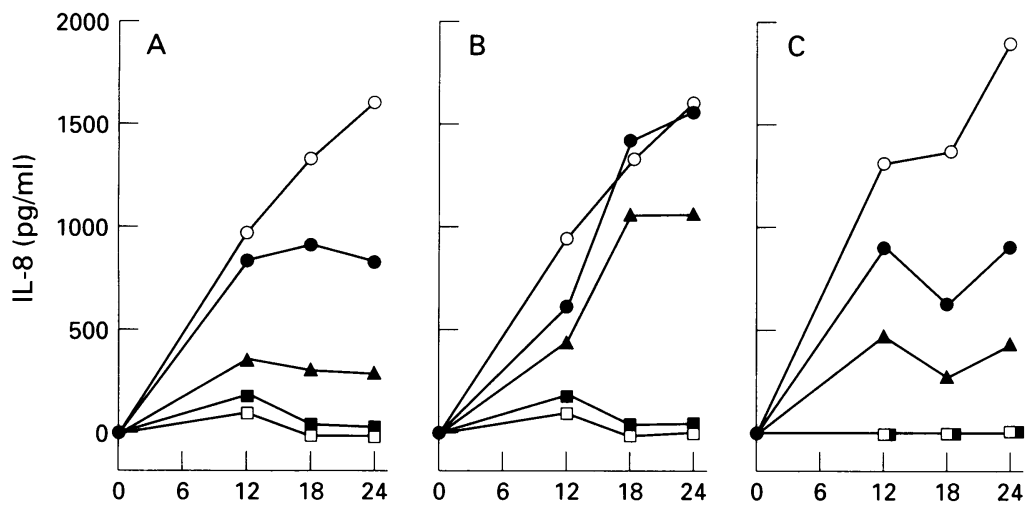

Length of incubation (hours)

Figure 3: Effect of lactobacilli on release of $I L-8$. H pylori No $130+\mathrm{L}$ salivarius $(A)$, $\mathrm{H}$ pylori $N o 130+\mathrm{L}$ brevis $(B)$, or $\mathrm{H}$ pylori $N o 135+\mathrm{L}$ salivarius $(C)$ was added to MKN45 cells. Open circles, $\mathrm{H}$ pylori, $10^{8}$; closed circles, $\mathrm{H}$ pylori, $10^{8}+$ lactobacillus, $10^{7}$; closed triangles, $\mathrm{H}$ pylori, $10^{8}+$ lactobacillus, $10^{8}$; closed squares, $\mathrm{H}$ pylori,

$10^{8}+$ lactobacillus, $10^{9}$; open squares, lactobacillus, $10^{9}$.

$H$ pylori (fig 3). Without the addition of lactobacilli, the amount of IL-8 accumulated in the culture supernatant increased progressively until 24 hours after the start of the culture (open circles). With addition of $10^{7} \mathrm{~L}$ salivarius, one tenth of the number of added $H$ pylori significantly reduced the amount of IL-8 in the supernatant (fig 3A), while a ten times larger number was required to accomplish such a significant reduction by the addition of $L$ brevis (fig 3B). The lactobacilli mediated suppression of IL-8 secretion was also observed when $H$ pylori No 135 instead of No 130 was used as the stimulator (fig $3 \mathrm{C}$ ). It was thus concluded that lactobacilli, especially $L$ salivarius, efficiently inhibit the attachment of $H$ pylori to gastric epithelial cells and the subsequent secretion of IL- 8 by these cells. It was also interesting to note that the lactobacilli themselves hardly stimulated these human gastric epithelial cell lines to secrete IL-8 in this assay (open squares). In addition, no cytotoxic effect was found in the cells of this culture based on a microscopic analysis using trypan blue.

INOCULATION OF H PYLORI INTO GF AND SPF MICE

The gnotobiotic murine system was then used to determine whether or not colonisation of the stomach by $H$ pylori can also be prevented by lactobacilli which can inhibit the attachment of $H$ pylori to the cells in vitro. As shown in fig 1 , we have confirmed that all of the $H$ pylori strains including No 130, No 112 (data not shown), and NCTC 11637 (data not shown) have the ability to adhere to gastric epithelial cells in a primary culture obtained by the enzymatic digestion of the stomachs from GF BALB/c mice. First, susceptibility to colonisation by $H$ pylori was compared between GF and SPF mice. Five-week-old mice were inoculated orally with $H$ pylori No 112 , No 130, or NCTC 11637, and the number of $\mathrm{CFU}$ of this bacterium colonising the stomach were counted (fig 4). In GF mice, all strains, including NCTC 11637, which has had no

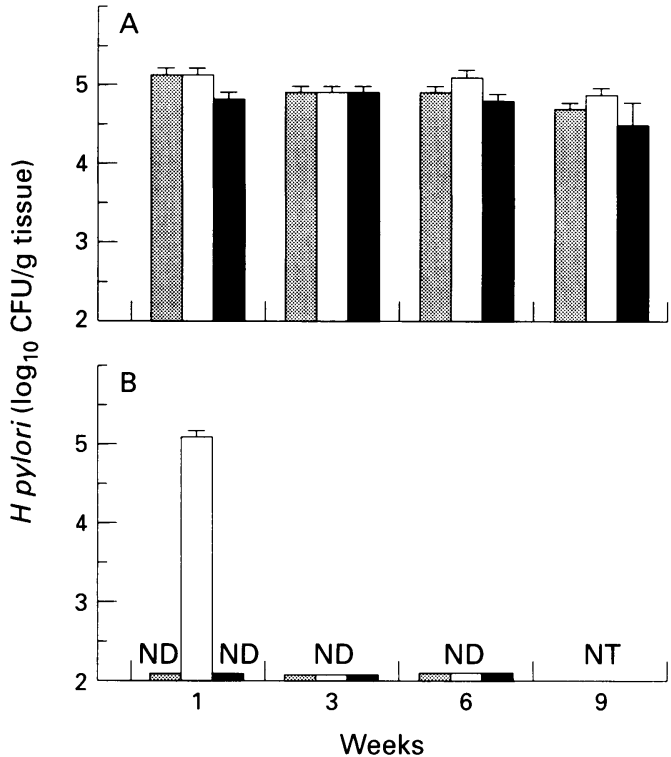

Figure 4: The number of $C F U$ of $\mathrm{H}$ pylori colonising the stomach of mice. $G F(A)$ and SPF $(B)$ mice were inoculated with $\mathrm{H}$ pylori strain No 112 (shaded columns), No 130 (open columns), or NCTC 11637 (closed columns). At three weekly intervals after inoculation, the stomachs were removed and the number of $\mathrm{H}$ pylori $C F U$ counted. The number of CFU per $g$ wet tissue is expressed on a log scale. Bars represent standard errors $(n=5) . N D$, not detected; NT, not tested.

report of successful colonisation in the animal model so far, colonised the stomach in large numbers (around $10^{5} \mathrm{CFU}$ per $\mathrm{g}$ tissue) one week after inoculation and still maintained such an overt infection nine weeks later (fig 4A). In SPF mice, however, no successful colonisation by any of these strains was found, while a transient colonisation by No 130 (open columns) was observed one week after inoculation (fig 4B). Examination of the specific IgG antibody titre to $H$ pylori also substantiated the success and failure of the infection in GF and SPF mice, respectively, such that a significant elevation of the serum antibody titre was found three weeks after inoculation of any strain of $H$ pylori in the GF mice while no such elevation was observed in the SPF mice (fig 5). Failure of the infection by $H$ pylori in SPF mice thus raised the possibility that the microflora already colonising the stomach of these mice may inhibit colonisation by the $H$ pylori inoculated later. Analysis of the composition of gastric bacterial flora in SPF mice revealed the predominant bacterial species to be lactobacilli, enterococci, and staphylococci in this order (table 1). Such findings strongly suggest that the inhibition of $H$ pylori colonisation by lactobacilli actually occurs in the stomach of SPF mice.

INFECTION OF THE GNOTOBIOTIC MURINE SYSTEM BY $H$ PYLORI

To confirm that $L$ salivarius, which is a strain highly capable of inhibiting the attachment of $H$ pylori to the cells in vitro, is also able to exert such an inhibitory effect on the colonisation and development of inflammatory lesions by $H$ pylori in the stomach, GF mice were initially dosed with $L$ salivarius by oral administration 


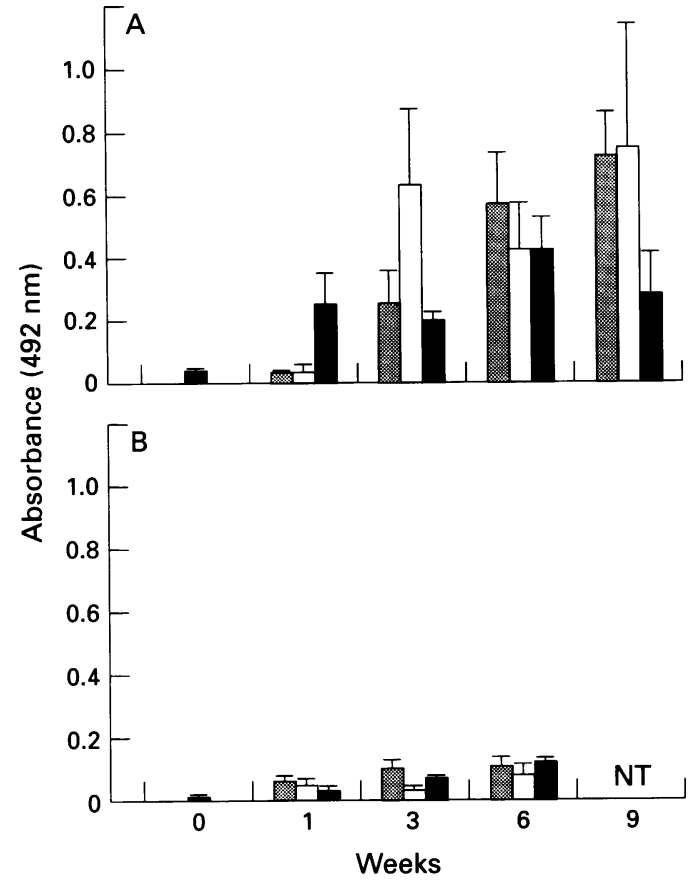

Figure 5: Serum antibody titre to $\mathrm{H}$ pylori. Serum from $G F(A)$ and SPF (B) mice used in the experiment shown in fig 4 was assayed to examine its IgG class antibody titre to $\mathrm{H}$ pylori. NT, not tested.

at four weeks and were then inoculated with $H$ pylori No 130 five weeks after birth (fig 6). The number of CFU of $L$ salivarius colonising the stomach was approximately $10^{8}$ per $\mathrm{g}$ tissue when examined just before the inoculation of $H$ pylori (data not shown) and one, three, and six weeks after inoculation (fig $6 \mathrm{~B}$, shaded columns). As a control, five-week-old GF mice were prepared and inoculated orally with $H$ pylori No 130 only. While the stomachs of GF mice were colonised with a large number of $H$ pylori (fig 6A, open columns), the gnotobiotic mice, which had already been colonised by $L$ salivarius, had no detectable $H$ pylori after inoculation of this bacterium (fig 6B). The gnotobiotes associated with the lactobacilli of murine stomach origin, consisting of $L$ acidophilus, $L$ delbrueckii, and $L$ fermentum, were also completely protected from colonisation by $H$ pylori (fig 6C).

In contrast, neither the gnotobiotic mice infected with $E$ faecalis (fig 6D) nor the gnotobiotic mice infected with $S$ aureus (fig $6 \mathrm{E}$ ) were able to inhibit colonisation by $H$ pylori, which was comparable to the results of the adherence assay in vitro in which both of these bacteria were unable to block the attachment of $H$ pylor

TABLE 1 Bacterial flora in the stomachs of mice

\begin{tabular}{ll}
\hline Bacterial group & Bacterial number \\
\hline Lactobacilli & $8 \cdot 5(0 \cdot 2)^{\star}$ \\
L acidophilus & $(\sim 90 \%)$ \\
L delbrueckii & $(\sim 10 \%)$ \\
L fermentum & $(\sim 10 \%)$ \\
Enterococci & $2 \cdot 9(0 \cdot 5)$ \\
Staphylococci & $2 \cdot 9(0 \cdot 2)$ \\
Enterobacteria & $2 \cdot 9(0 \cdot 4)$ \\
Helicobacter & $\mathrm{ND}$ \\
\hline
\end{tabular}

Results expressed as $\log _{10}$ per $g$ tissue (mean (SE)). $\star_{n}=3$; ND, not detected.

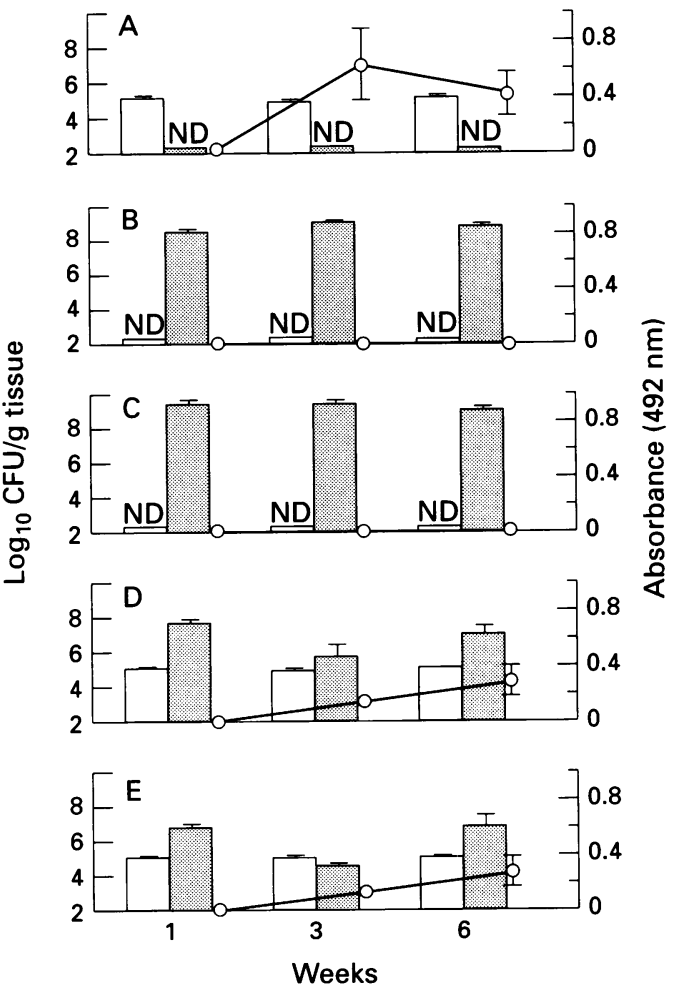

Figure 6: The number of $\mathrm{H}$ pylori and antibody titre in gnotobiotic mice. $G F(A)$, L salivarius monoassociated gnotobiotic (B), murine stomach origin lactobacilli associated gnotobiotic $(C)$, E faecalis monoassociated gnotobiotic (D), and $\mathrm{S}$ aureus monoassociated gnotobiotic (E) mice were inoculated with $\mathrm{H}$ pylori No 130, and the number of CFU of $\mathrm{H}$ pylori (open columns) and the other bacteria (shaded columns) colonising their stomachs were counted one, three, and six weeks after inoculation. Serum Ig $G$ antibody titres to $\mathrm{H}$ pylori were measured simultaneously (open circles). Bars represent the standard errors $(n=5)$. ND, not detected.

to the cells (fig 1D). A significant elevation of the IgG antibody titre to $H$ pylori in GF, $E$ faecalis infected, and $S$ aureus infected mice together with the lack of any such rise in lactobacilli associated gnotobiotes, again confirmed the success and failure of infection by $H$ pylori in these two groups of mice, respectively (fig 6 , open circles). A histological examination of the gastric mucosa nine weeks after inoculation of $H$ pylori No 130 demonstrated active gastritis in GF mice but no such lesions in $L$ salivarius infected gnotobiotic mice (fig 7). GF mice infected with No 112 did not develop any significant inflammatory lesions in the stomach (data not shown).

Finally, we investigated whether $L$ salivarius given after $H$ pylori colonisation can eliminate inhabiting $H$ pylori. GF mice infected with $H$ pylori at the age of five weeks were inoculated orally once a day for three consecutive days and thereafter once at 10,11 , and 12 weeks with $1 \times 10^{8} \mathrm{~L}$ salivarius, and were sacrificed at 13 weeks of age for examination (fig 8). In the mice treated with $L$ salivarius, the number of $H$ pylori in the stomach decreased to less than one hundredth of that of $H$ pylori in the nontreated mice (open columns) and the antibody titre to $H$ pylori almost became undetectable (hatched columns), thus demonstrating the potential efficacy of $L$ salivarius as a probiotic against $H$ pylori. 

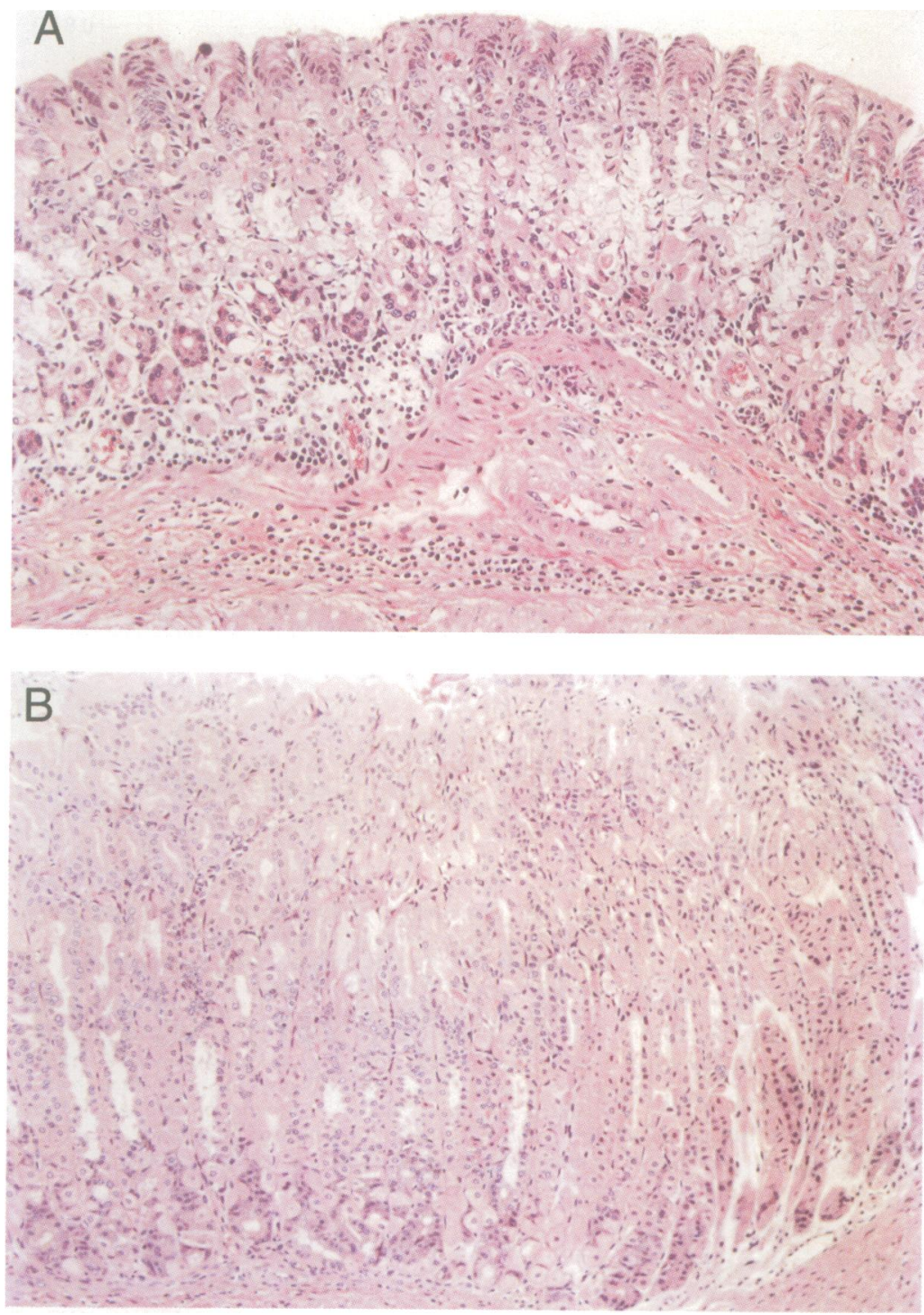

Figure 7: Gastric pathology of mice inoculated with $\mathrm{H}$ pylori. Nine weeks after inoculation with $\mathrm{H}$ pylori No 130, GF $(A)$ and $\mathrm{L}$ salivarius monoassociated gnotobiotic mice $(B)$ were sacrificed to examine the gastric pathology of the stomach. Note that the antral epithelial layer becomes atrophic and is associated with infiltration of numerous inflammatory cells in GF but not in gnotobiotic mice. Original magnification, $\times 60$.

\section{Discussion}

The adhesion of $H$ pylori to gastric epithelial cells is a primary event in the development of infection. A few putative cell receptors for $H$ pylori attachment have been identified including phosphatidylethanolamine ${ }^{18}$ ganglioside GM3,${ }^{19}$ and Lewis B antigens. ${ }^{20}$ Since most of these structures are also expressed on cells other than human, $H$ pylori can thus adhere to these non-human cells including those of murine origin as reported elsewhere. ${ }^{15}$ Nevertheless it was difficult to colonise experimental animals by $H$ pylori, except when these animals were maintained in GF and decontaminated conditions as in the cases of piglets ${ }^{21}$ and mice, ${ }^{11}$ respectively. In the present study, SPF mice were also unable to be colonised by $H$ pylori whereas GF mice were colonised easily by this bacterium. The difficulty in the colonisation by $H$ pylor in conventional mice may be explained by the large number of indigenous lactobacilli in their stomachs as shown in the present study. On the other hand, a very small

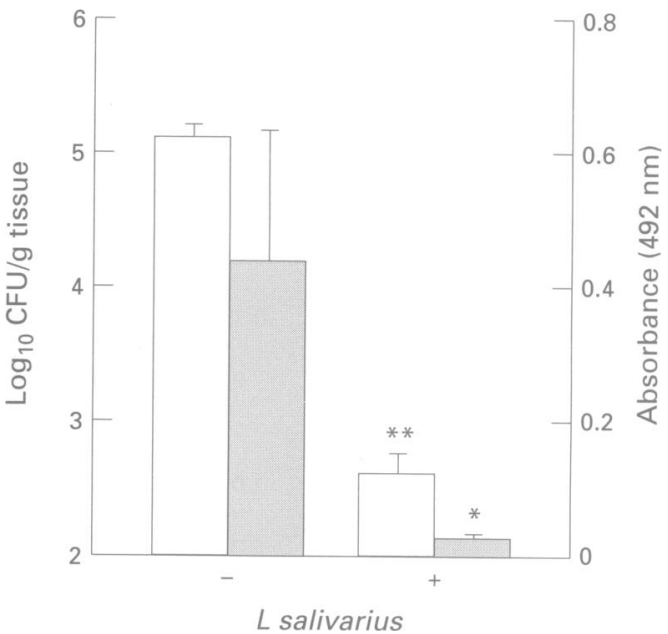

Figure 8: Effect of $\mathrm{L}$ salivarius given after colonisation by $\mathrm{H}$ pylori. $G F$ mice infected with $\mathrm{H}$ pylori at five weeks of age were orally inoculated with $1 \times 10^{8} \mathrm{~L}$ salivarius once $a$ day for three consecutive days at nine weeks of age and then once every week until 12 weeks of age. At 13 weeks of age, these mice were sacrificed to examine the number of

$\mathrm{H}$ pylori in their stomach (open columns) and the IgG class antibody titre to $\mathrm{H}$ pylori (closed columns). Bars represent standard errors $(n=5)$. Control mice ( $\mathrm{L}$ salivarius (-)) were infected with $\mathrm{H}$ pylori but were not inoculated with L salivarius. ${ }^{\star \star} p<0.01 ;{ }^{\star} p<0.05$ by Student's t test.

number of lactobacilli inhabiting the stomachs of humans may permit $H$ pylori to colonise this organ easily.

Recently, Marchetti et $a l^{22}$ reported the successful colonisation by clinical isolates of $H$ pylori strains but not NCTC 11637, an established laboratory strain, in conventional and SPF mice. These findings may thus imply that such clinical isolates can adhere to the receptors on the cells so strongly as to overcome any competition with other indigenous bacteria such as lactobacilli, while NCTC 11637 is unable to attach itself so strongly. In contrast to their animal model, our GF murine system was able to be infected with any strain of $H$ pylori including NCTC 11637. Moreover in our animal model, active gastritis resembling human disease was observed in the infection with No 130, a vacuolating cytotoxin positive strain, but not with No 112 , a vacuolating cytotoxin negative strain. This finding was consistent with the results shown by Marchetti et $a l^{22}$ and therefore demonstrated our system to be a reliable animal model of $H$ pylori infection.

Lactobacilli have been introduced into several fermented dairy products. There is a large body of evidence showing the positive role of exogenous lactobacilli in the prevention and treatment of GI disorders. ${ }^{23}$ Lactobacilli adhere to cells of the GI tract by secreting a proteinaceous component, which serves as a bridge between the bacteria and eukaryotic cell receptors, although its precise nature still remains to be elucidated. ${ }^{24}$ This bacterium has been reported to inhibit the adhesion of many kinds of pathogenic enterobacteria to intestinal cells. ${ }^{25}$ While it is still unclear how lactobacilli inhibit the attachment of $H$ pylori to gastric epithelial cells in the present study, nonspecific steric hindrance rather than a specific blockade of receptor sites is the most likely 
mechanism, as lactobacilli can inhibit the adhesion of a large variety of bacteria, while each adheres to its particular receptor on the cells. Bhatia et $a l^{9}$ reported that $L$ acidophilus inhibits the growth of $H$ pylori in vitro, and thus concluded that this inhibitory effect is dependent on an extracellular secretory product, probably lactic acid. Such products secreted by lactobacilli may partially participate in the inhibition of colonisation by $H$ pylori in the stomachs of SPF and lactobacilli associated gnotobiotic mice.

Vaccination in addition to antimicrobial therapy will thus be needed in the campaign against $H$ pylori. However, a vaccine against $H$ pylori is still associated with some problems such as the unclarified effectiveness in prevention of infection and the resultant symptoms and potential noxious cross reaction with host tissue. The principle of probiotics, which involves feeding live bacteria to the host as a prophylactic or treatment for many intestinal diseases, has long been attempted. ${ }^{26}$ If it is possible to establish a harmless organism in the gastric mucosa, colonisation by $H$ pylori can be prevented. The results of the present study suggest that lactobacillus is a good candidate for a probiotic against $H$ pylori as it can completely prevent the colonisation and subsequent gastric lesions caused by $H$ pylori in the stomach, possibly due to the inhibition of attachment. Furthermore, lactobacillus itself is considered to be a harmless organism in the gastric mucosa when it colonises the stomach, as this study showed that no pathological lesions developed in the stomach of gnotobiotic mice colonised by $L$ salivarius. Harmlessness of this bacterium in vitro was substantiated by the lack of significant production of IL- 8 by the lactobacilli attached to the gastric epithelial cells in culture. Screening to find a more suitable strain of lactobacillus other than $L$ salivarius as a probiotic against $H$ pylori is underway.

Part of this study was financially assisted by the Sasagawa Fund for Medical Research, Tokyo, Japan.

1 Marshall BJ. Helicobacter pylori. Am $\mathcal{F}$ Gastroenterol 1994; 89: S116-28.

2 Graham DY, Adam E, Reddy GT, Agarwal JP, Agarwal R, Evancs DG, et al. Seroepidemiology of Helicobacter pylori infection in India. Comparison of developing and pylori inection in India. Comparison of developin

3 Dunn BE, Roop RM, Sung C-C, Sharma SA, Perez-Perez GI, unn BE, Roop RM, Sung C-C, Sharma SA, Perez-Perez GI,
Blaser MJ. Identification and purification of a cpn60 Blaser MJ. Identification and purification of a cpn60
heatshock protein homolog from Helicobacter pylori. heatshock protein homolog from

4 Negrini R, Lisato L, Zanella I, Cavazzini L, Vallanacci S, Ghielmi S, et al. Helicobacter pylori infection induces antibodies cross-reacting with human gastric mucosa. Gastroenterology 1991; 101: 437-45.
5 Smoot DT, Resau JH, Naab T, Desbordes BC, Gilliam T, Mobley HLT, et al. Adherence of Helicobacter pylori to cultured human gastric epithelial cells. Infect Immun 1993; 61: $350-5$.

6 Dytoc M, Gold B, Louie M, Huesca M, Fedorko L Sherman $\mathrm{P}$, et al. Comparison of Helicobacter pylori and Sherman $\mathrm{P}$, et al. Comparison of Helicobacter pylori and attaching-effacing Escherichia coli adhes

7 Crabtree JE, Farmery SM, Lindley IJD, Figura N, Peichl P, Tompkins DS. CagA/cytotoxic strains of Helicobacter pylori and interleukin-8 in gastric epithelial cell lines. $\mathcal{F}$ pylori and interleukin-8 in gastr

8 Donaldson RM Jr, Toskes PP. The relationship of enteric bacterial populations to gastrointestinal function and disease. In: Sleisenger MH, Fordtran, JS, editors. Gastrointestinal disease, 4 th edn. Philadelphia: Saunders, 1989: $107-13$

9 Bhatia SJ, Kochar N, Abraham P, Nair NG, Mehta AP Lactobacillus acidophilus inhibits growth of Campylobacter pylori in vitro. F Clin Microbiol 1989; 27: 2328-30.

10 Karita M, Li O, Cantero D, Okita K. Establishment of a small animal model for human Helicobacter pylori infection using germ-free mouse. Am $\mathcal{F}$ Gastroenterol 1994 89: $208-13$.

11 Ohnishi N, Karita M. Evaluation of new therapy for eradication of $\mathrm{H}$. pylori infection in nude mouse model. Am f Gastroenterol 1996; 91 : 174-5.

12 Kamiya S, Kai M, Ozawa A, Kobayashi H, Shirai T, Miwa T, et al. Characteristics of vacuolating toxin produced by Helicobacter pylori. Eur 7 Gastroenterol Hepatol 1994; 6: S23-7.

13 Dunn BE, Altman M, Campbell GP. Adherence of Helicobacter pylori to gastric carcinoma cells; analysis by flow cytometry. Rev Infect Dis 1991; 13: 657-64.

4 Yamamoto-Osaki $\mathrm{T}$, Yamaguchi $\mathrm{H}$, Taguchi $\mathrm{H}$, Ogata $\mathrm{S}$ Kamiya S. Adherence of Helicobacter pylori to cultured human gastric carcinoma cells. Eur $\mathcal{f}$ Gastroenterol Hepatol 1995; 7: S89-92.

15 Kobayashi Y, Okazaki K, Murakami K. Adhesion of Helicobacter pylori to gastric epithelial cells in primary cultures obtained from stomachs of various animals. Infect Immun 1993; 61: 4058-63.

16 Umehara K, Yamanaka M, Hashimoto K, Sasaki S Nitrogen retention in germ-free and conventional mice reared on an antigen-free diet and the significance of the reared on an antigen-free diet and the significance of the appearance of prote

17 Takakura A, Kagiyama N, Sakurai Y, Suzuki H, Kobayashi N, Terada E. Detection of Sendai virus antibody in mouse and guinea pig sera by an enzyme-linked immunosorbent assay with protein A. Exp Anim 1988; 37: 279-83.

18 Gold BJ, Huesca $M$, Sherman PM, Lingwood CA Helicobacter mustelae and Helicobacter pylori bind to common lipid receptors in vitro. Infect Immun 1993; 61: 2632-8.

19 Slomiany BL, Piotrowski J, Samanta A, VanHorn K, Murty VLN, Slomiany A. Campylobacter pylori colonization factor shows specificity for lactosylceramide sulfate and GM3 ganglioside. Biochem Intern 1989; 19: 929-36.

20 Boren T, Falk P, Roth KA, Larson G, Normark S. Attachment of Helicobacter pylori to human gastric epithelium
mediated by blood group antigens. Science 1993; 262: mediated

21 Krakowka S, Morgan DR, Kraft WG, Leunk RD. Establishment of gastric Campylobacter pylori infection in the neonatal gnotobiotic piglet. Infect Immun 1987; 55: 2789-96

22 Marchetti M, Arico B, Burroni D, Figure N, Rappuoli R, Ghiara P. Development of a mouse model of Helicobacter pylori infection that mimics human disease. Science 1995 267: 1655 .

23 Reid G, Bruce AW, McGroarty JA, Cheng KJ, Costerton JW. Is there a role for Lactobacilli in prevention of urogenital and intestinal infection. Clin Microbiol Rev 1990; 3 : 335-44.

24 Conway PL, Kjelleberg S. Protein-mediated adhesion of Lactobacillus fermentum strain 737 to mouse stomach Lactobacillus fermentum strain 737 to mouse stomach
squamous epithelium. f Gen Microbiol 1989; 135: squamous

25 Bernet MF, Brassart D, Neerer JR, Servin AL. Lactobacillus acidophilus LA 1 binds to cultured human intestinal cell lines and inhibits cell attachment and cell invasion by enterovirulent bacteria. Gut 1994; 35: 483-9.

26 Fuller R. Probiotics in man and animals. $\mathcal{f}$ Appl Bacterio 1989; 66: 365-78. 